\title{
Migrações internas e mobilidade pendular: uma análise sobre os processos recentes de crescimento populacional e integração regional no leste fluminense
}

\author{
Internal migration and commuting: an analysis of recent \\ processes of population growth and regional integration in \\ eastern Rio de Janeiro
}

Hisrael Passarelli-Araujo [a] [D, Joseane de Souza [b] (D),

Denise Cunha Tavares Terra [b] [D

[a] Universidade Federal de Minas Gerais (UFMG), Centro de Desenvolvimento e Planejamento Regional (Cedeplar),

Belo Horizonte, MG, Brasil

[b] Universidade Estadual do Norte Fluminense Darcy Ribeiro (UENF), Campos dos Goytacazes, RJ, Brasil

Como citar: Passarelli-Araujo, H., Souza, J., \& Terra, D. C. T. (2021). Migrações internas e mobilidade pendular: uma análise sobre os processos recentes de crescimento populacional e integração regional no leste fluminense. urbe. Revista Brasileira de Gestão Urbana, v.13, e20210130. https://doi.org/10.1590/2175-3369.013.e20210130

\section{Resumo}

Os movimentos da população são elementos fundamentais para a compreensão dos processos de crescimento populacional e articulação entre as cidades. No contexto do estado do Rio de Janeiro, as mudanças recentes em termos de origens, destinos e intensidade dos fluxos observadas na porção leste fluminense sugerem formas distintas de relação entre os diferentes espaços e reforça a necessidade de compreender o papel desses movimentos na região. Dada a reconhecida importância do tema para os estudos urbanos e regionais, este artigo busca analisar o papel das migrações internas para o crescimento populacional e dos movimentos pendulares no processo de integração regional. A análise privilegia os indicadores tradicionais nos estudos de mobilidade populacional, construídos a partir dos dados censitários de 2010. As evidências encontradas sugerem que o crescimento demográfico ainda permanece concentrado nas maiores cidades, que a redistribuição da população tem sido favorável aos municípios centrais e que Macaé tem se colocado como município potencialmente integrador do mercado de trabalho regional. 0 artigo também apresenta três questões emergentes na análise dos movimentos populacionais que podem pavimentar o caminho para novas pesquisas e fomentar novas discussões sobre os rumos que a mobilidade espacial da população na região pode seguir no futuro.

Palavras-chave: Migração. Pendularidade. Arranjos populacionais. Rio de Janeiro.

\section{Abstract}

Population movements are fundamental elements for understanding processes of population growth and articulation between cities. In the context of the state of Rio de Janeiro, recent changes in terms of origins, destinations and intensity of flows observed in the eastern Rio de Janeiro suggest different forms of relationship

HPA é mestrando em Demografia, bacharel em Administração Pública, e-mail: hisraelpassarelli@gmail.com JS é professora associada, doutora em Demografia, e-mail: joseanedesouza.souza@gmail.com DCTT é professora associada, doutora em Geografia, e-mail: deniseterra@gmail.com 
between the different spaces and reinforce the need to understand the role of these movements in the region. Given the recognized importance of the theme for urban and regional studies, this article analyzes the role of internal migration for population growth and commuting in the process of regional integration. The analysis favors traditional indicators in population mobility studies, built from 2010 Brazilian census data. The evidence suggests that population growth is still concentrated in the largest cities, that population redistribution has been favorable to central municipalities and that Macaé has positioned itself as a municipality potentially integrating the regional labor market. may contribute for new research and encourage new discussions about the directions that the spatial mobility of the population in the region may take in the future.

Keywords: Migration. Commuting. Population arrangements. Rio de Janeiro.

\section{Introdução}

A mobilidade populacional é um elemento fundamental para a compreensão dos processos de crescimento, expansão e articulação entre as cidades. A mudança que os movimentos populacionais vêm experimentando nas últimas décadas em termos de composição, distância, causas e consequências sugere formas distintas de relação entre os diferentes espaços e reforça a necessidade de compreender o papel desses movimentos no processo mais amplo de crescimento populacional e redistribuição espacial da população.

No Brasil, o processo de urbanização até os anos 1970 esteve baseado na vertente da concentração: concentração da dinâmica econômica, da população nas grandes metrópoles e das migrações (Baeninger, 2010). O ponto de inflexão deste processo histórico é a década de 1980, uma década marcada pela transformação na dinâmica econômica, social e demográfica no país por meio de diversos fatores, dentre os quais destacam-se: o arrefecimento do processo de concentração espacial populacional nas grandes metrópoles; o avanço da transição demográfica e da fecundidade, levando à diminuição da pressão demográfica até então existente em determinadas áreas do território brasileiro; e o arrefecimento do crescimento populacional (Cunha et al., 2020). Essas transformações repercutiram nos processos de redistribuição espacial da população e na configuração urbana do país (Baeninger, 2010; Silva et al., 2016).

A maior novidade no processo de urbanização brasileira nas últimas duas décadas não vem das grandes metrópoles, mas sim das suas áreas do entorno e dos novos arranjos populacionais que emergem fora do contexto metropolitano (IBGE, 2015). Na dinâmica do processo de redistribuição espacial da população, Baeninger (2010) ressalta que as novas espacialidades vêm assumindo importância crescente, já que elas podem ser capazes tanto de absorver quanto de reter grande parte dos fluxos migratórios que, anteriormente, se dirigiam às grandes concentrações metropolitanas. Esse cenário sugere que "a rede urbana brasileira não apenas se interioriza em termos de desenvolvimento econômico, mas também pela dinâmica demográfica conectada entre municípios de regiões não metropolitanas" (Ojima \& Marandola Jr., 2012, p. 108).

Um bom exemplo é a dinâmica territorial observada na porção leste do estado do Rio de Janeiro, que se destaca como um aspecto relevante da urbanização brasileira (IBGE, 2015). As atividades ligadas à extração de produção de petróleo e gás na Bacia de Campos contribuíram para uma intensificação do fluxo de pessoas e para uma reconfiguração da hierarquia regional das cidades e do mercado de trabalho, resultando nos arranjos populacionais de Macaé-Rio das Ostras, Cabo Frio e Campos dos Goytacazes, cada vez mais conectados à economia global (Silva, 2015; Terra \& Azevedo, 2019). Caso o dinamismo econômico nesta região venha a aumentar o movimento de pessoas entre estes três arranjos, é possível o surgimento de uma nova região metropolitana no território fluminense (Souza \& Terra, 2017).

Dada a reconhecida importância do tema para os estudos urbanos e regionais, este artigo busca analisar o papel das migrações internas para o crescimento populacional regional e dos movimentos pendulares no processo de integração entre os municípios do leste fluminense. A temática justifica-se pelo papel que a migração possui como elemento importante na formação da população local e regional. Ela afeta mais do que apenas o número total de habitantes. Com o tempo, uma população pode ser alterada ou transformada à medida que as pessoas percebem suas intenções de entrar ou sair de uma determinada área (Siegel \& Swanson, 2004). Identificar as origens e os destinos dos migrantes possibilita: estabelecer o direcionamento 
dos fluxos populacionais; mensurar a capacidade de absorver, reter e expulsar migrantes; avaliar a condição da economia regional; e discutir a importância desses movimentos para o processo de acumulação capitalista.

No contexto da pendularidade, são esses deslocamentos que tornam evidentes os espaços mais integrados à dinâmica regional e também os que disponibilizam seu território para habitação, trabalho e/ou estudo (Passarelli-Araujo \& Souza, 2020). Os movimentos pendulares revelam os desafios institucionais compartilhados entre os municípios que, em muitos casos, passam despercebidos pelas políticas públicas; eles também têm reconhecida importância para a compreensão das relações regionais em áreas de forte industrialização que necessitam de grandes contingentes de mão de obra, que nem sempre a cidade central por si só é capaz de garantir (Ojima \& Marandola Jr., 2012).

Este trabalho está organizado em mais quatro seções, além desta introdutória. A segunda seção descreve a metodologia e caracteriza a área de estudo. A terceira discute a contribuição das migrações internas no processo de crescimento populacional do leste fluminense e a quarta analisa a pendularidade como um importante indicativo de integração regional. Por fim, sintetizamos as principais conclusões e apresentamos algumas questões emergentes para fomentar o debate sobre os rumos que a mobilidade espacial da população na região pode seguir no futuro.

\section{Considerações metodológicas e caracterização da área de estudo}

Para analisar o papel das migrações internas para o crescimento populacional regional e dos movimentos pendulares no processo de integração entre os municípios do leste fluminense, utilizamos informações diretas referentes aos movimentos migratórios e pendulares contidas no censo demográfico de 2010. Além dos dados censitários, também utilizamos a população estimada dos municípios em 2020, fornecidas pelo IBGE (2020)1.

0 recorte espacial adotado contempla os arranjos populacionais² de 'Macaé-Rio das Ostras', 'Campos dos Goytacazes' e 'Cabo Frio', formados pelos municípios que vão desde São João da Barra até Arraial do Cabo (Figura 1). São municípios possuem um intenso movimento pendular para estudo e trabalho, com tamanha integração que justifica considerá-los como um único nó da rede urbana (IBGE, 2015).

A atualização da hierarquia urbana brasileira, divulgada pelo IBGE no estudo Regiões de Influência das Cidades (IBGE, 2018), classifica os arranjos populacionais de 'Macaé-Rio das Ostras' e 'Cabo Frio' como Capitais Regionais nível C33, passando a acompanhar 'Campos dos Goytacazes'. Essa atualização reforça o papel exercido pelos municípios da região como centros urbanos com alta concentração de atividades de gestão, mas com um alcance menor em termos de região de influência em comparação com a metrópole fluminense. Ao todo, esses três arranjos populacionais somam, atualmente, cerca de 1,4 milhão de habitantes.

\footnotetext{
1 As estimativas de população publicadas anualmente pelo IBGE são elaboradas com base nas informações sobre a população enumerada no Censo Demográfico 2010 e as informações mais recentes sobre as componentes do crescimento demográfico (mortalidade, fecundidade e migração). Dadas as transformações ocorridas na dinâmica populacional, as projeções são monitoradas continuamente e passam por revisões periódicas, tanto para a incorporação de novas informações, quando são detectadas alterações nas hipóteses previstas para as componentes, quanto para a atualização de sua metodologia de cálculo (IBGE, 2020).

2 Arranjos Populacionais são recortes territoriais que consistem em agrupamentos de dois ou mais municípios, onde há uma forte integração populacional devido aos movimentos pendulares para trabalho ou estudo, ou devido à contiguidade entre as manchas urbanizadas principais (IBGE, 2015).

${ }^{3}$ Capitais Regionais são centros urbanos com alta concentração de atividades de gestão, mas com alcance menor em termos de região de influência em comparação com as Metrópoles. Na última atualização do estudo Regiões de Influência das Cidades em 2018, as Capitais Regionais apresentavam três subdivisões (A, B e C), que se diferenciam em termos de porte populacional.
} 


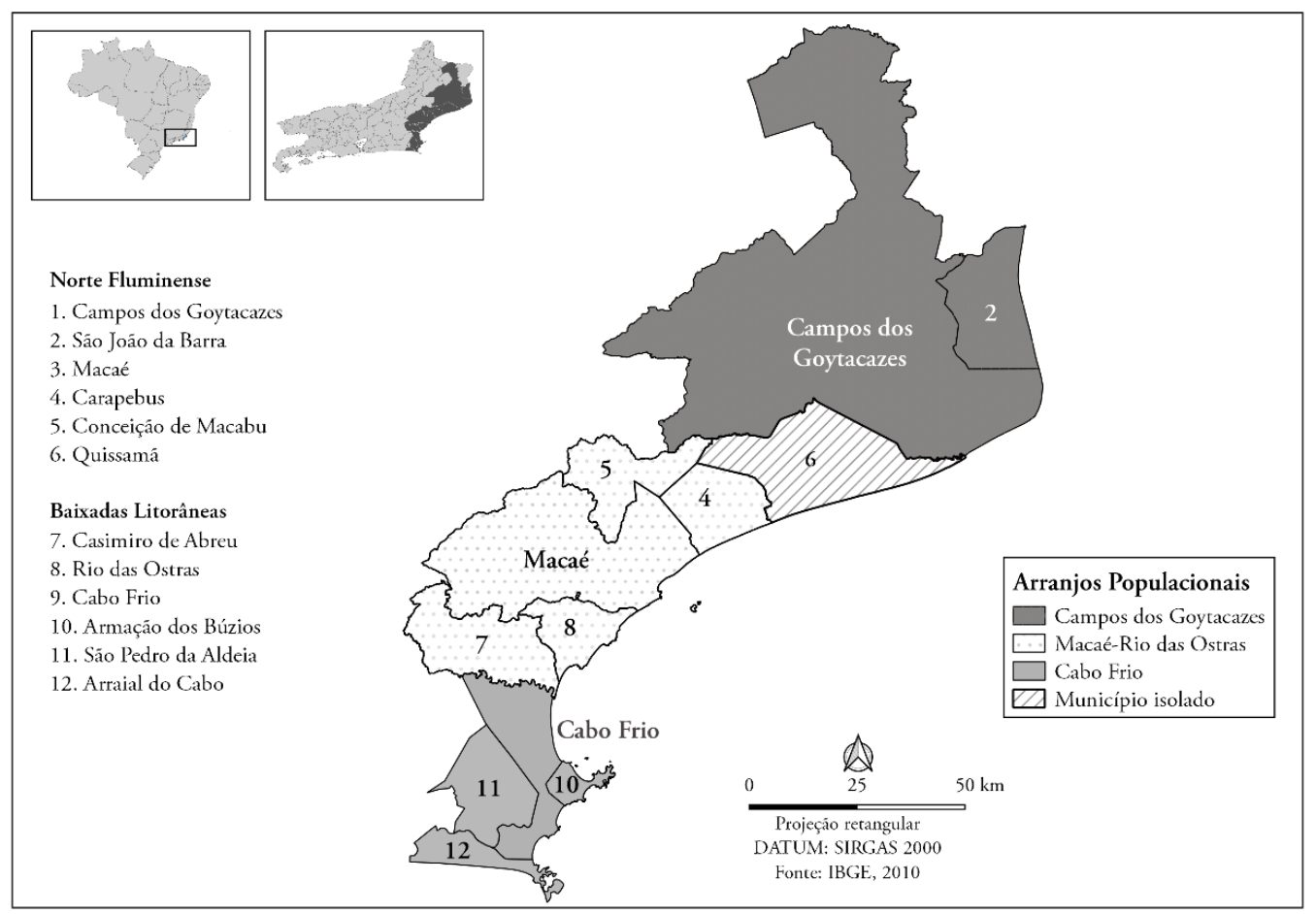

Figura 1 - Composição dos arranjos populacionais do leste fluminense, segundo mesorregião. Fonte: IBGE (2010).

Como é possível observar na Figura 1, em termos espaciais, tais arranjos abrangem praticamente todo o vetor leste, excluindo-se apenas os municípios de Quissamã e São Francisco de Itabapoana. Embora não pertença a nenhum dos três arranjos estudados, Quissamã foi incluído no estudo, pois Passarelli-Araujo e Souza (2020) constataram que este município apresenta um nível considerável de integração com os demais municípios por trabalho e estudo na região.

Antes de prosseguir para a apresentação dos indicadores utilizados na pesquisa, é importante trazer uma definição conceitual precisa das duas formas de mobilidade espacial (migração e pendularidade) que serão investigadas nesse trabalho. Essa distinção conceitual deve ser mais bem qualificada em meios acadêmicos e na esfera do planejamento público a partir do momento em que assume uma centralidade nas discussões sobre as estratégias de desenvolvimento e articulação regional (Barbieri, 2015). Novas formas distintas de mobilidade refletem diferentes impactos sobre níveis de desenvolvimento, portanto, "uma maior precisão conceitual pode revelar distintos matizes ou gradientes de formas de mobilidade que, por sua vez, requerem formas diferenciadas de atuação das políticas públicas” (Barbieri, 2015, p. 35).

0 conceito de migração refere-se às mudanças permanentes de residência entre unidades espaciais predefinidas (Carvalho \& Rigotti, 1998). A própria definição do conceito já sugere que nem todos os movimentos geográficos podem ser qualificados como migração. Um exemplo é a pendularidade. Trata-se de uma forma de mobilidade que não envolve mudança de residência, muito embora seja equivocadamente tratada como "migração pendular". A pendularidade se refere, em seu sentido mais amplo, ao deslocamento realizado por um indivíduo entre unidades espaciais distintas, cujo local de residência difere do local de trabalho ou de estudo (Pereira \& Herrero, 2009).

Além do conceito mais amplo de pendularidade, o Censo de 2010 também possibilita a análise desses deslocamentos em seu sentido mais estrito. Estritamente, a pendularidade se refere ao deslocamento realizado por um indivíduo que trabalha e/ou estuda em municípios diferentes do de residência, e que retorna para casa diariamente, independentemente do tempo habitualmente gasto nesse deslocamento (Souza et al., 2015).

Dado o objetivo do trabalho, a análise não se restringirá à pendularidade de trabalhadores e de estudantes que retornam para casa diariamente. 0 motivo de adotarmos o conceito mais amplo da pendularidade se deve às especificidades dos contratos de trabalho - regime de 14 dias trabalhados por 14 dias de folga, de 21×21, 28x28 e 14x21 - de muitos dos trabalhadores das indústrias que operam na região. 
Essa especificidade é um fator adicional que possibilita a dissociação entre o local de trabalho e o local de moradia para um grande número de trabalhadores, à medida em que permite que muitos deles residam em locais mais distantes do seu local de trabalho. 0 conceito de pendularidade ampliada foi também adotado para a captação dos pendulares por motivo estudo, de forma a possibilitar a compatibilização das matrizes para a estimativa da pendularidade total. Ainda que esta escolha seja de cunho metodológico, ela apresenta vantagens, pois permite captar um número significativo de estudantes que se deslocam semanalmente e retornam para o município de residência apenas nos finais de semana ou feriados.

As informações censitárias referentes à pendularidade por estudo e trabalho não podem ser diretamente somadas, pois estaríamos incorrendo no erro de dupla contagem daqueles pendulares que trabalham e estudam no mesmo município. Para não incorrermos nesse erro, excluímos da matriz de estudo todos os indivíduos que trabalham e estudam no mesmo município, dado que eles já estão incluídos na matriz trabalho.

No contexto das migrações, o quesito utilizado foi o de data fixa, o qual indaga o lugar de residência cinco anos antes da data de referência do recenseamento. A partir desse quesito, calculamos algumas das principais medidas convencionais de migração: imigrantes (I), emigrantes (E), saldo migratório (SM), taxa líquida de migração (TLM), índice de eficácia migratória (IEM) e o índice de reposição populacional (IRP).

Os saldos migratórios são obtidos por meio da diferença entre imigrantes e emigrantes em um determinado período (I - E). Embora eles tenham reconhecida importância na caracterização da dinâmica migratória regional, eles sozinhos são incapazes de definir o efeito líquido da migração, o potencial de perda, rotatividade ou retenção migratória. É necessário analisar a relação estabelecida entre o saldo de migrantes e a população total, como forma de mensurar a intensidade da dinâmica migratória no território.

O impacto do saldo migratório no crescimento de uma população pode ser analisado a partir da taxa líquida de migração (TLM), que corresponde ao quociente entre o saldo migratório e a população observada no final do período (Carvalho et al. 2016). Para facilitar a interpretação, a TLM comumente é multiplicada por 100. Assim, a TLM corresponde ao efeito líquido da migração no crescimento da população em um determinado território. A TLM, caso seja positiva, indica a proporção da população observada no final do período resultante do processo migratório; se for negativa, será interpretada como a proporção em que a população observada no segundo censo seria acrescida na ausência de migração (Carvalho et al., 2016). Essa interpretação da TLM enfatiza o papel da migração sobre o crescimento ou decrescimento populacional entre dois períodos.

O índice de eficácia migratória (IEM) é uma ferramenta que pode ser aplicável a diferentes tipos de fluxos para identificar a capacidade de atração, evasão ou rotatividade migratória em cada município. Ele é obtido através da relação entre o saldo migratório e o volume total de migrantes (SM / I + E) (Baeninger, 2000). 0 IEM varia entre -1 e 1 . Valores próximos de 1 indicam uma maior capacidade de absorção de população da unidade territorial em análise. Por outro lado, os valores que se aproximam de - 1 indicam uma maior evasão populacional. Valores próximos de zero indicam a ocorrência de rotatividade migratória - conceito referente às áreas que apresentam fluxos semelhantes de entrada e saída. Teoricamente, o resultado zero também pode ser resultante da ausência de migrações. Neste caso, não haveria rotatividade migratória. Nesse trabalho, classificaremos os municípios em sete grandes grupos sugeridos por Baeninger (2000):

- $\quad-0,51$ a -1,00: área de forte evasão migratória;

- $\quad-0,30$ a -0,50: área de média evasão migratória;

- $\quad-0,10$ a -0,29: área de baixa evasão migratória;

- 0,00 a $\pm 0,09$ : área de rotatividade migratória;

- $\quad 0,10$ a 0,29: área de baixa absorção migratória;

- 0,30 a 0,50: área de média absorção migratória;

- 0,51 a 1,00: área de forte absorção migratória.

O índice de reposição populacional (IRP) é um indicador que sintetiza o número de entradas de migrantes em relação ao número de saídas (imigração / emigração). Aliado ao IEM, esse indicador favorece 
uma maior aproximação sobre o conhecimento da dinâmica migratória nas áreas de estudo em termos de entradas, saídas, retenção ou expulsão dos imigrantes (Baeninger, 2000).

\section{O papel das migrações no processo de crescimento populacional do leste fluminense}

Os movimentos populacionais, sobretudo as migrações internas, são um dos elos mais importantes entre as profundas mudanças estruturais e a reconfiguração funcional das cidades do leste fluminense (Souza \& Terra, 2020). Embora os arranjos populacionais estudados apresentassem dinâmicas de produção e ocupação distintas no passado, a notícia da descoberta de petróleo na plataforma continental marítima na Bacia de Campos, em 1973, foi um pacto territorial verdadeiramente transformador que inaugurou um novo ciclo econômico na região (Piquet et al., 2008).

O início das atividades de exploração do petróleo trouxe um rápido crescimento da população urbana, especialmente em Macaé - município escolhido para sediar a Unidade de Operação da Petrobras na Bacia Petrolífera de Campos (Souza \& Terra, 2017). As novas possibilidades de trabalho assalariado e com maior remuneração estimularam o movimento de pessoas para a região, revertendo a tendência de esvaziamento demográfico no período anterior (Souza \& Terra, 2020). As transformações territoriais, ensejadas pelas alterações das dinâmicas demográfica, econômica e urbana, alteraram a hierarquia regional existente e Macaé passou a ter um posicionamento estratégico para o desenvolvimento do estado do Rio de Janeiro (Terra \& Azevedo, 2019).

Nos períodos recentes, a estimativa é que a população regional tenha ultrapassado a marca de 1,4 milhão de habitantes em 2020, superando em 61\% as 885 mil pessoas registradas em 2000 (Tabela 1). A tendência de concentração populacional nos núcleos dos arranjos populacionais (Macaé, Cabo Frio e Campos dos Goytacazes) já era observada desde 2000. Em 2020, aproximadamente $70 \%$ da população residia nesses municípios, segundo as estimativas populacionais fornecidas pelo IBGE. Uma das formas de se melhor observar essa tendência é analisar a contribuição relativa do núcleo e dos demais municípios para o crescimento absoluto dos arranjos populacionais e da região em questão.

Entre os anos de 2000 e 2010, o ritmo de crescimento médio anual em todos os municípios selecionados foi superior ao ritmo médio estadual (1,1\% a.a.). Dentre os municípios de crescimento mais acelerado, destacam-se Rio das Ostras (10,7\% a.a), Casimiro de Abreu (4,7\% a.a), Macaé (4,5\% a.a), Carapebus (4,3\% a.a). Quando se analisa a contribuição do núcleo para o crescimento demográfico dos arranjos populacionais, nota-se que esses municípios ainda respondem à maior parcela do incremento total da população. Esse cenário sugere que o crescimento populacional permanece concentrado e que o crescimento das maiores cidades, ainda que a taxas mais baixas, é o que explica o crescimento populacional da região.

Souza e Frutuozo (2018), ao analisarem os processos de expansão urbana e interiorização do crescimento no estado do Rio de Janeiro entre 1980 e 2010, demonstram que esses ritmos relativamente elevados de crescimento populacional já eram observados desde os anos 1980. Os autores fornecem evidências de que, pelo menos desde aquela década, os municípios do leste fluminense se estabelecem como a principal frente de interiorização do estado do Rio de Janeiro. Os valores elevados também refletem a forma pela qual a dinâmica do mercado imobiliário de Macaé, a expansão do mercado de trabalho da indústria petrolífera e parapetrolífera, a melhoria da estrutura viária e as desigualdades regionais em termos de oportunidades de trabalho e estudo impactaram o movimento da população (Souza \& Terra, 2015).

As estimativas populacionais realizadas pelo IBGE para 2020 sugerem uma redução do ritmo de crescimento populacional, para todos os municípios selecionados, embora eles sigam crescendo a um ritmo superior à média estadual, de 0,8\% ao ano. 
Migrações internas e mobilidade pendular

Tabela 1 - Arranjos Populacionais selecionados: População, Taxa de Crescimento e Participação relativa no incremento absoluto (2000-2020)

\begin{tabular}{|c|c|c|c|c|c|c|c|c|c|}
\hline \multirow[t]{2}{*}{$\begin{array}{l}\text { Arranjos Populacionais e seus respectivos } \\
\text { municípios }\end{array}$} & \multicolumn{3}{|c|}{ População residente } & \multicolumn{2}{|c|}{$\begin{array}{c}\text { Taxa de crescimento } \\
\text { médio anual }\end{array}$} & \multicolumn{2}{|c|}{$\begin{array}{c}\text { Participação relativa } \\
\text { no incremento } \\
\text { absoluto do Arranjo } \\
\text { Populacional }\end{array}$} & \multicolumn{2}{|c|}{$\begin{array}{l}\text { Participação relativa } \\
\text { no incremento } \\
\text { absoluto da região }\end{array}$} \\
\hline & 2000 & 2010 & $2020 *$ & $2000-2010$ & $2010-2020$ & $2000-2010$ & $2010-2020$ & $2000-2010$ & $2010-2020$ \\
\hline 'CABO FRIO' & 232.136 & 329.377 & 401.497 & 3,5 & 2,0 & 100,0 & 100,0 & 30,1 & 29,7 \\
\hline Armação dos Búzios & 18.204 & 27.560 & 34.477 & 4,1 & 2,2 & 9,6 & 9,6 & 2,9 & 2,9 \\
\hline Arraial do Cabo & 23.877 & 27.715 & 30.593 & 1,5 & 1,0 & 3,9 & 4,0 & 1,2 & 1,2 \\
\hline Cabo Frio & 126.828 & 186.227 & 230.378 & 3,8 & 2,1 & 61,1 & 61,2 & 18,4 & 18,2 \\
\hline São Pedro da Aldeia & 63.227 & 87.875 & 106.049 & 3,3 & 1,9 & 25,3 & 25,2 & 7,6 & 7,5 \\
\hline 'CAMPOS DOS GOYTACAZES' & 434.850 & 496.478 & 547.591 & 1,3 & 1,0 & 100,0 & 100,0 & 19,1 & 21,1 \\
\hline Campos dos Goytacazes & 407.168 & 463.731 & 511.168 & 1,3 & 1,0 & 91,8 & 92,8 & 17,5 & 19,6 \\
\hline São João da Barra & 27.682 & 32.747 & 36.423 & 1,7 & 1,1 & 8,2 & 7,2 & 1,6 & 1,5 \\
\hline 'MACAÉ-RIO DAS OSTRAS' & 218.480 & 382.321 & 501.719 & 5,6 & 2,7 & 100,0 & 100,0 & 50,8 & 49,2 \\
\hline Carapebus & 8.666 & 13.359 & 16.586 & 4,3 & 2,2 & 2,9 & 2,7 & 1,5 & 1,3 \\
\hline Casimiro de Abreu & 22.152 & 35.347 & 45.041 & 4,7 & 2,4 & 8,1 & 8,1 & 4,1 & 4,0 \\
\hline Conceição de Macabu & 18.782 & 21.211 & 23.398 & 1,2 & 1,0 & 1,5 & 1,8 & 0,8 & 0,9 \\
\hline Macaé & 132.461 & 206.728 & 261.501 & 4,5 & 2,4 & 45,3 & 45,9 & 23,0 & 22,6 \\
\hline Rio das Ostras & 36.419 & 105.676 & 155.193 & 10,7 & 3,8 & 42,3 & 41,5 & 21,5 & 20,4 \\
\hline TOTAL & 885.466 & 1.208 .176 & 1.450 .807 & 3,1 & 1,8 & - & - & 100,0 & 100,0 \\
\hline ESTADO DO RJ & 14.391 .282 & 15.989 .929 & 17.366 .189 & 1,1 & 0,8 & - & - & - & - \\
\hline BRASIL & 169.799 .170 & 190.755 .799 & 211.755 .692 & 1,2 & 1,0 & - & - & - & - \\
\hline
\end{tabular}

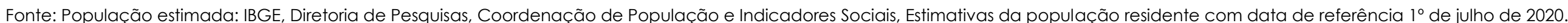
IBGE (2000; 2010). 
As migrações internas contribuíram fortemente para a aceleração do crescimento (Souza \& Frutuozo, 2018). A alta atratividade que esses municípios exercem sobre a população migrante associa-se às possibilidades de emprego na indústria petrolífera e parapetrolífera; às possibilidades de emprego no setor de turismo; e às transferências de moradia de residentes da Região Metropolitana do Rio de Janeiro para alguns municípios da região (Souza et al., 2019). A Tabela 2 sintetiza os resultados encontrados para os movimentos migratórios restritos aos municípios selecionados. A título de exemplo, a TLM de Carapebus entre 2005 e 2010 foi de 5,5\%. Esse valor demonstra que 5,5\% da população total do município em 2010 é resultante do processo migratório. Foi o maior valor observado no âmbito dos municípios analisados, indicando que o município recebe muitos imigrantes provenientes desses municípios. Rio das Ostras também se destaca como o segundo principal receptor líquido de migrantes na região, com uma TLM de $4,8 \%$.

Tabela 2 - Municípios selecionados: Indicadores de migração total de data-fixa entre os municípios selecionados do leste fluminense (2005-2010)

\begin{tabular}{lrrrrrr}
\hline \multirow{2}{*}{ Municípios selecionados } & \multicolumn{7}{c}{ Migração entre os municípios selecionados } \\
\cline { 2 - 7 } & \multicolumn{1}{c}{ I } & \multicolumn{1}{c}{ E } & \multicolumn{1}{c}{ SM } & \multicolumn{1}{c}{ TLM } & \multicolumn{1}{c}{ IEM } & \multicolumn{1}{c}{ IRP } \\
\hline Armação dos Búzios & 734 & 759 & -25 & $-0,1$ & $-0,02$ & 1,0 \\
Arraial do Cabo & 923 & 1.173 & -250 & $-0,9$ & $-0,12$ & 0,8 \\
Cabo Frio & 4.105 & 5.469 & -1.364 & $-0,7$ & $-0,14$ & 0,8 \\
São Pedro da Aldeia & 3.916 & 1.387 & 2.529 & 2,9 & 0,48 & 2,8 \\
Campos dos Goytacazes & 2.158 & 9.341 & -7.183 & $-1,5$ & $-0,62$ & 0,2 \\
São João da Barra & 1.848 & 627 & 1.221 & 3,7 & 0,49 & 2,9 \\
Carapebus & 1.035 & 301 & 734 & 5,5 & 0,55 & 3,4 \\
Casimiro de Abreu & 1.648 & 841 & 807 & 2,3 & 0,32 & 2,0 \\
Conceição de Macabu & 649 & 673 & -24 & $-0,1$ & $-0,02$ & 1,0 \\
Macaé & 4.926 & 6.869 & -1.943 & $-0,9$ & $-0,16$ & 0,7 \\
Quissamã & 744 & 360 & 384 & 1,9 & 0,35 & 2,1 \\
Rio das Ostras & 7.192 & 2.078 & 5.114 & 4,8 & 0,55 & 3,5 \\
'Cabo Frio' & $\mathbf{9 . 6 7 8}$ & $\mathbf{8 . 7 8 8}$ & $\mathbf{8 9 0}$ & $\mathbf{0 , 3}$ & $\mathbf{0 , 0 5}$ & $\mathbf{1 , 1}$ \\
'Campos dos Goytacazes' & $\mathbf{4 . 0 0 6}$ & $\mathbf{9 . 9 6 8}$ & $-\mathbf{5 . 9 6 2}$ & $-\mathbf{1 , 2}$ & $-\mathbf{0 , 4 3}$ & $\mathbf{0 , 4}$ \\
'Macaé-Rio das Ostras' & $\mathbf{1 5 . 4 5 0}$ & $\mathbf{1 0 . 7 6 2}$ & $\mathbf{4 . 6 8 8}$ & $\mathbf{1 , 2}$ & $\mathbf{0 , 1 8}$ & $\mathbf{1 , 4}$ \\
Total & $\mathbf{2 9 . 8 7 8}$ & $\mathbf{2 9 . 8 7 8}$ & - & - & - & - \\
\hline
\end{tabular}

Nota: I = Imigrantes; E = Emigrantes; SM = Saldo Migratório (I - E); TLM = Taxa Líquida de Migração (SM / População no final do período); IEM = Índice de Eficácia Migratória (SM / (I + E)); IRP = Índice de Reposição Populacional (I / E). Fonte: IBGE (2010).

Curiosamente, no âmbito dos municípios que apresentam saldos negativos, estão os municípios de Macaé, Cabo Frio e Campos dos Goytacazes, que são polos dos arranjos populacionais estudados (Tabela 2). Essa situação vai ao encontro dos achados de Souza e Terra (2015) e sugere que parte dos imigrantes reside em cidades vizinhas onde possivelmente os custos são menores, seja no setor imobiliário ou no de serviços.

Implicitamente, a hipótese levantada por Souza e Terra (2015) é que existe uma ampla relação de complementaridade entre a migração e a pendularidade na região. Outros estudos assinalados por Colla et al. (2020), em outros contextos regionais, indicam que migração para as cidades vizinhas e a subsequente pendularidade para os polos regionais ocorre principalmente por uma maior oferta residencial e preços mais baixos dos imóveis no entorno, além de uma estrutura de transporte que possibilite o deslocamento desses indivíduos e, parcialmente, pela expansão das oportunidades de emprego nessas áreas.

A relação entre migração e pendularidade também decorre dos efeitos importantes do mercado imobiliário (e do uso da terra urbana). A pressão do mercado imobiliário pode contribuir para o aumento da mobilidade dos trabalhadores imigrantes em direção aos locais mais distantes do centro ou do núcleo, que apresentam menores custos de habitação. Como a mobilidade espacial da população é indissociável da mobilidade espacial dos bens de consumo e de produção, de capitais, de empresas, de tecnologias e de 
informações, a localização e relocalização do capital imobiliário e dos investimentos públicos na região exercem considerável influência na dinâmica migratória regional (Paganoto, 2012).

Em relação à dinâmica migratória da região estudada, observa-se que o arranjo populacional de 'Cabo Frio' é predominantemente uma área de rotatividade migratória na região. Há certa equivalência em termos de reposição migratória na região (IRP $=1,1)$. Significa dizer que havia 11 entradas para cada 10 pessoas que emigravam da região no período analisado.

Campos dos Goytacazes, o município mais populoso e de maior extensão territorial, é caracterizado como uma área de forte evasão migratória. Apesar de ter sido, por muitos anos, centralidade histórica do Norte Fluminense, Campos é atualmente caracterizado como um espaço perdedor de população. A cada duas pessoas que entraram, dez saíram (IRP = 0,2). A mesma situação é observada no arranjo populacional homônimo, que, por sua vez, é o único com IEM negativo e abaixo do nível de reposição migratória.

O município de Macaé chama a atenção por se caracterizar como uma área de evasão migratória. Isso sugere que existe uma seletividade migratória, impulsionada pelo mercado imobiliário de Macaé, caracterizado pelo alto preço da terra, mas também pelos mercados imobiliários de Rio das Ostras, Casimiro de Abreu e Carapebus, que ainda praticam preços relativamente mais baixos (Souza \& Terra, 2017). Uma segunda possibilidade se relaciona à realização de investimentos na estrutura viária que conecta esses municípios. Esses investimentos têm favorecido a emigração nessas direções à medida que permite que as pessoas acessem o mercado de trabalho por meio do movimento pendular, em um espaço relativamente curto de tempo (Souza \& Terra, 2017).

No contexto da dinâmica migratória existente entre os municípios selecionados e o restante do estado do Rio de Janeiro, com exceção de Campos dos Goytacazes, todos os municípios selecionados apresentam saldos migratórios positivos. 0 impacto das migrações no crescimento populacional do conjunto de municípios foi de 4,3\%. No período entre 2005 e 2010, a região registrou a chegada de 20 imigrantes para cada 10 emigrantes (IRP = 2). No caso de Campos, as maiores perdas populacionais se dão para municípios do Norte Fluminense, mais especificamente para Macaé e Rio das Ostras.

Rio das Ostras é o maior receptor líquido de imigrantes. A TLM de Rio das Ostras entre 2005 e 2010 foi de 22,9\%, o maior valor observado no âmbito dos municípios analisados. 0 município também se caracteriza como área de forte absorção migratória: para cada 10 pessoas que saíram, havia 75 que imigraram para o município.

Tabela 3 - Indicadores de migração total de data fixa (2005-2020) entre Municípios selecionados e os demais municípios do estado do Rio de Janeiro (2005-2010)

\begin{tabular}{lrrrrrr}
\hline \multirow{2}{*}{ Municípios selecionados } & \multicolumn{7}{c}{ Migração Total } \\
\cline { 2 - 7 } & \multicolumn{1}{c}{ I } & \multicolumn{1}{c}{ E } & \multicolumn{1}{c}{ SM } & \multicolumn{1}{c}{ TLM } & \multicolumn{1}{c}{ IEM } & \multicolumn{1}{c}{ IRP } \\
\hline Armação dos Búzios & 2.899 & 1.410 & 1.489 & 5,4 & 0,35 & 2,1 \\
Arraial do Cabo & 3.189 & 1.568 & 1.621 & 5,8 & 0,34 & 2,0 \\
Cabo Frio & 21.911 & 9.810 & 12.101 & 6,5 & 0,38 & 2,2 \\
São Pedro da Aldeia & 11.024 & 3.398 & 7.626 & 8,7 & 0,53 & 3,2 \\
Campos dos Goytacazes & 7.797 & 15.228 & -7.431 & $-1,6$ & $-0,32$ & 0,5 \\
São João da Barra & 2.369 & 825 & 1.544 & 4,7 & 0,48 & 2,9 \\
Carapebus & 1.616 & 337 & 1.279 & 9,6 & 0,65 & 4,8 \\
Casimiro de Abreu & 5.678 & 1.651 & 4.027 & 11,4 & 0,55 & 3,4 \\
Conceição de Macabu & 1.155 & 929 & 226 & 1,1 & 0,11 & 1,2 \\
Macaé & 15.923 & 11.084 & 4.839 & 2,3 & 0,18 & 1,4 \\
Quissamã & 1.635 & 577 & 1.058 & 5,2 & 0,48 & 2,8 \\
Rio das Ostras & 27.903 & 3.727 & 24.176 & 22,9 & 0,76 & 7,5 \\
'Cabo Frio' & $\mathbf{3 9 . 0 2 3}$ & $\mathbf{1 6 . 1 8 6}$ & $\mathbf{2 2 . 8 3 7}$ & $\mathbf{6 , 9}$ & $\mathbf{0 , 4 1}$ & $\mathbf{2 , 4}$ \\
'Campos dos Goytacazes' & $\mathbf{1 0 . 1 6 6}$ & $\mathbf{1 6 . 0 5 3}$ & $-\mathbf{5 . 8 8 7}$ & $\mathbf{- 1 , 2}$ & $-\mathbf{0 , 2 2}$ & $\mathbf{0 , 6}$ \\
'Macaé-Rio das Ostras' & $\mathbf{5 2 . 2 7 5}$ & $\mathbf{1 7 . 7 2 8}$ & $\mathbf{3 4 . 5 4 7}$ & $\mathbf{9 , 0}$ & $\mathbf{0 , 4 9}$ & $\mathbf{2 , 9}$ \\
Total & $\mathbf{1 0 3 . 0 9 9}$ & $\mathbf{5 0 . 5 4 4}$ & $\mathbf{5 2 . 5 5 5}$ & $\mathbf{4 , 3}$ & $\mathbf{0 , 3 4}$ & $\mathbf{2 , 0}$ \\
\hline
\end{tabular}

Nota: I = Imigrantes; E = Emigrantes; SM = Saldo Migratório (I - E); TLM = Taxa Líquida de Migração (SM / População no final do período); IEM = Índice de Eficácia Migratória (SM / (I + E)); IRP = Índice de Reposição Populacional (I / E). Fonte: IBGE (2010). 
O caso específico de Macaé demonstra que, diferentemente do contexto em que os movimentos migratórios foram restritos aos municípios selecionados, o município se configura como área de absorção migratória, apesar de baixa. Essa situação sugere que a capacidade de absorção populacional de Macaé ultrapassa os limites territoriais do leste fluminense.

\section{Os movimentos pendulares como indicadores de integração regional}

Na literatura recente, está bem estabelecido que os movimentos pendulares podem ser utilizados como um importante indicativo de integração e urbanização do território (Lobo et al., 2018; Moura et al., 2005; Moura et al., 2013). Órgãos estatísticos de diferentes países como a França (Julien, 2000) e os Estados Unidos (Federal Register, 2000) utilizam essas informações para esse propósito. No contexto brasileiro, a pendularidade é um critério tradicional para a identificação de áreas urbanas integradas e foi utilizado no passado como um dos critérios para a delimitação das primeiras regiões metropolitanas do país (Galvão \& Faissal, 1969).

Alguns trabalhos disponibilizam uma série de indicadores para avaliar a integração regional por meio dos movimentos pendulares. Um deles é o indicador desenvolvido por Lobo et al. (2018) e adaptado por Passarelli-Araujo e Souza (2020) para o contexto do leste fluminense. Esse indicador incorpora três dimensões analíticas da pendularidade: pendularidade interna; conectividade pendular; e pendularidade em direção ao núcleo regional.

Uma característica comum aos trabalhos recentes (Cruz \& Terra, 2020; Passarelli-Araujo \& Souza, 2020) é o reconhecimento da importância de Macaé como centralidade regional. Embora Campos dos Goytacazes seja maior, mais populoso e apresente uma economia mais diversificada, é em torno de Macaé que o tecido urbano regional tem se reorganizado. Macaé tem se colocado como: principal destino dos movimentos pendulares totais; maior estabelecedor de conexões efetivas com outros municípios; e principal indutor do aumento dos movimentos pendulares das cidades vizinhas, que, por sua vez, "emprestam" ${ }^{4}$ o seu território à cidade de Macaé para atender às demandas por moradia e àquelas do setor industrial e de serviços (Araujo, 2016; Passarelli-Araujo \& Souza, 2020).

A Figura 2 retrata os pontos discutidos por Passarelli-Araujo e Souza (2020) para o ano de 2010, por meio do diagrama de Sankey, uma forma de representação visual das origens e destinos dos fluxos pendulares. A altura dos retângulos que representam cada município é proporcional à quantidade do fluxo existente entre o município de origem e o de destino. Note que Macaé é o município centralizador de entradas na região. Macaé se conecta a todos os municípios. Esse padrão sugere uma relação de interdependência entre os municípios: aqueles de menor porte precisam do mercado de trabalho de Macaé para absorção de sua mão de obra e, por outro lado, se não fossem os movimentos pendulares, muitos postos de trabalho em Macaé não seriam preenchidos ou o seriam apenas pelas migrações internas (Souza \& Terra, 2017).

É provável que o desenvolvimento destes intensos fluxos pendulares na porção leste fluminense estejam associados à noção de cidades-região (Scott et al., 2001) pois, o que se observa é que a dinâmica econômica dos municípios não metropolitanos passa a depender cada vez mais dos fluxos sociais, políticos e demográficos entre eles (Ojima \& Marandola Jr., 2012). Essa integração reforça a necessidade de estimular respostas político-institucionais para além da escala municipal - o que justificaria, teoricamente, falar em cidade-região (Arrais, 2008). A contribuição deste conceito não se restringe ao reconhecimento de processos demográficos que integram as cidades aos seus contextos regionais, mas tem como mérito a necessidade de fomentar a discussão política em espaços integrados, marcados por desafios institucionais comuns (Arrais, 2008).

\footnotetext{
4 Este conceito se refere à prática de empréstimo de territórios entre cidades, estabelecendo lógicas de relações, interfuncionalidades e contiguidades, para atender à demanda, seja por moradia, seja industrial e de serviços especializados (Araujo, 2016).
} 


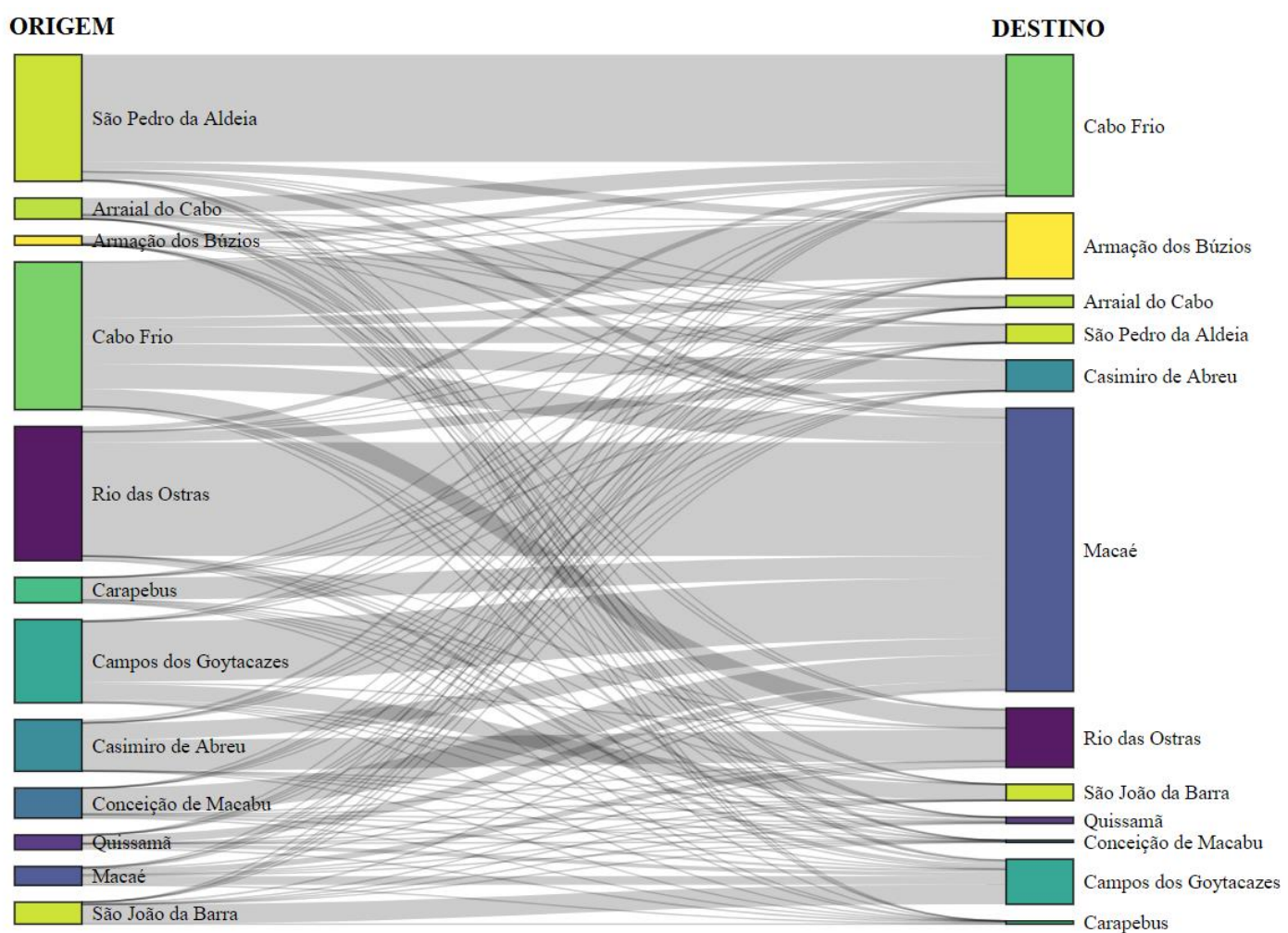

Figura 2 - Municípios selecionados: origem, destino e densidade dos movimentos pendulares (2010). Fonte: IBGE (2010),

Quando analisamos a proporção dos movimentos pendulares por trabalho em relação à população economicamente ativa residente no município, chamam a nossa atenção os municípios de Carapebus Conceição de Macabu, São Pedro da Aldeia, Rio das Ostras e Casimiro de Abreu. Se adotarmos o critério estabelecido por Ojima et al. (2010) para identificação de "cidades-dormitório" - 40\% da população ocupada realizando estes movimentos - Carapebus, por exemplo, se aproximaria dessa classificação, dado que 39\% da população ocupada sai para trabalhar em outra cidade, sobretudo em Macaé.

Tabela 4 - Municípios selecionados: proporção dos movimentos pendulares por trabalho e estudo (2010)

\begin{tabular}{|c|c|c|c|c|c|c|}
\hline \multirow[b]{2}{*}{$\begin{array}{l}\text { Municípios } \\
\text { selecionados }\end{array}$} & \multicolumn{3}{|c|}{ Pendularidade por motivo de trabalho } & \multicolumn{3}{|c|}{ Pendularidade por motivo de estudo } \\
\hline & $\begin{array}{c}\text { Trabalhadores } \\
\text { pendulares }\end{array}$ & $\begin{array}{c}\text { Trabalhadores } \\
\text { ocupados } \\
\text { residentes }\end{array}$ & $\begin{array}{c}\text { Proporção } \\
\text { (\%) }\end{array}$ & $\begin{array}{l}\text { Estudantes } \\
\text { pendulares }\end{array}$ & $\begin{array}{l}\text { População } \\
\text { residente que } \\
\text { estudava }\end{array}$ & $\begin{array}{c}\text { Proporção } \\
\text { (\%) }\end{array}$ \\
\hline Armação dos Búzios & 341 & 13.596 & 2,5 & 694 & 7.863 & 8,8 \\
\hline Arraial do Cabo & 1.608 & 12.573 & 12,8 & 827 & 8.190 & 10,1 \\
\hline Cabo Frio & 11.928 & 84.792 & 14,1 & 4.801 & 57.199 & 8,4 \\
\hline Carapebus & 2.372 & 6.081 & 39,0 & 612 & 3.752 & 16,3 \\
\hline $\begin{array}{l}\text { Campos dos } \\
\text { Goytacazes }\end{array}$ & 8.618 & 186.957 & 4,6 & 731 & 145.898 & 0,5 \\
\hline Casimiro de Abreu & 3.986 & 17.236 & 23,1 & 1.864 & 10.513 & 17,7 \\
\hline $\begin{array}{l}\text { Conceição de } \\
\text { Macabu }\end{array}$ & 3.073 & 9.709 & 31,7 & 455 & 6.372 & 7,1 \\
\hline Macaé & 1.069 & 102.811 & 1,0 & 1.044 & 62.182 & 1,7 \\
\hline Quissamã & 1.199 & 8.621 & 13,9 & 472 & 6.585 & 7,2 \\
\hline Rio das Ostras & 12.817 & 50.493 & 25,4 & 2.842 & 30.798 & 9,2 \\
\hline São João da Barra & 1.481 & 14.424 & 10,3 & 1.065 & 9.760 & 10,9 \\
\hline São Pedro da Aldeia & 10.395 & 37.672 & 27,6 & 4.021 & 26.697 & 15,1 \\
\hline Total & 58.887 & 544.965 & 10,8 & 19.428 & 375.809 & 5,2 \\
\hline
\end{tabular}

Fonte: IBGE (2010). 
Ao analisar o peso da pendularidade por motivo de estudo em cada município (Tabela 4), observa-se um fluxo pendular significativo nos municípios de Casimiro de Abreu, onde $17,7 \%$ da população que estuda frequenta escola ou creche em outro município; Carapebus (16,3\%), São Pedro da Aldeia $(15,1 \%)$, São João da Barra (10,9\%) e Arraial do Cabo (10,1\%). A pendularidade por estudo originária em Campos dos Goytacazes e em Macaé são inexpressivas. Isso se explica pela concentração de reconhecidas Instituições de ensino médio e superior nestes municípios, o que os torna o destino principal de muitos indivíduos.

\section{Considerações finais e questões emergentes na análise dos movimentos populacionais}

Este trabalho buscou analisar o papel dos movimentos populacionais no processo de crescimento e integração regional no leste fluminense. Os resultados observados sugerem que os movimentos migratórios tiveram uma reconhecida importância para o crescimento populacional dos arranjos analisados. Esse crescimento permanece concentrado nas maiores cidades. 0 processo incipiente de metropolização em curso na região tem sido marcado pela redistribuição da população favorável aos municípios centrais, estimulada pela emigração dos municípios do entorno em direção às demais cidades dos arranjos populacionais estudados.

O município de Macaé chama a atenção por se caracterizar como uma área de evasão de migrantes no contexto das migrações restritas aos municípios analisados. Esse cenário sugere a existência de uma seletividade migratória, que, por sua vez, é impulsionada pelo mercado imobiliário de Macaé e dos municípios do entorno. Por outro lado, quando se analisam as migrações entre Macaé e o restante do estado do Rio de Janeiro, o município se configura como área de absorção migratória e não mais como perdedor de população. Isso sugere que a capacidade de absorção populacional de Macaé ultrapassa os limites territoriais do leste fluminense.

No contexto dos movimentos pendulares, Macaé é o município centralizador de entradas na região. Ele é, ao mesmo tempo, o maior retentor de seus trabalhadores e estudantes. Macaé se conecta a todos os municípios. Esse padrão sugere uma relação de interdependência entre eles: aqueles de pequeno porte precisam do mercado de trabalho de Macaé para absorção de sua mão de obra e Macaé depende da mão de obra dos migrantes e dos pendulares para preencher os postos de trabalho no município.

Em relação às estimativas populacionais municipais em 2020, caso os pressupostos adotados pelo IBGE em relação ao comportamento da fecundidade, mortalidade e migração se verificassem, todos os municípios estudados apresentariam um crescimento populacional acima da média estadual. Alguns superariam, inclusive, a média nacional. Este cenário é apenas hipotético, pois as estimativas populacionais municipais não incorporam as mudanças conjunturais causadas pela forte crise econômica experimentada pelo estado do Rio de Janeiro no período pós-2010 e os seus desdobramentos na dinâmica populacional da região. No âmbito dos municípios economicamente mais dinâmicos e altamente dependentes da indústria do petróleo, essas estimativas possivelmente se distanciam do real perfil sociodemográfico da população recente. No entanto, só será possível confirmar ou refutar essa hipótese com os dados do próximo Censo Demográfico de 2022, o que reforça a importância de sua realização para avaliar as mudanças populacionais ocorridas nesses municípios no período recente.

Embora a literatura regional tenha progredido significativamente nos estudos sobre os movimentos da população no leste fluminense, sobretudo nos municípios produtores de petróleo da Bacia de Campos, ainda existem questões emergentes que merecem a atenção dos pesquisadores em investigações futuras. Essas questões não se restringem ao recorte espacial abordado no artigo e podem ser ampliadas para diferentes contextos.

A primeira delas se relaciona à forma pela qual as migrações alteraram a composição demográfica da população regional nos últimos anos, enfatizando a diversidade de experiências entre os diferentes municípios. No contexto atual, a migração tem substituído a fecundidade e a mortalidade como o principal agente de mudança populacional em muitos países e em recortes territoriais mais desagregados 
(Rodríguez-Vignoli \& Rowe, 2018). Compreender e determinar como a migração altera a composição da população desses espaços cada vez mais conectados às economias globais é fundamental para fornecer insumos ao planejamento de políticas públicas que respondam às necessidades da população municipal em termos de educação, saúde, transporte, moradia e trabalho. A segunda questão emergente na análise dos movimentos populacionais se refere aos impactos da migração sob uma perspectiva ainda pouco discutida pela literatura regional recente: a dos municípios de origem, sobretudo os de pequeno porte. Grande parte dos estudos enfatiza o papel das migrações no lugar de destino, especialmente nos municípios mais populosos da região como Macaé e Campos dos Goytacazes, mas deixam em segundo plano a discussão sobre a forma pela qual a intensa saída da população pode impactar as cidades que "emprestam" o seu território para que os centros regionais consigam responder às demandas por moradia ou às demandas setor industrial e de serviços.

Compreender o papel das migrações sob a perspectiva da origem permitirá discussões mais aprofundadas sobre seletividade migratória, dado que os imigrantes não são elementos aleatórios da população de origem, mas indivíduos com características bem definidas (Lee, 1966). A análise de seletividade requer uma comparação entre os migrantes e a população que permaneceu no lugar de origem, não aquela para a qual eles foram selecionados. Na verdade, é impossível ter certeza se os migrantes são selecionados ou não, quando os relacionamos com as características da população de destino. Nesses casos, é possível fazer incursões sobre a vantagem do imigrante em relação à população de destino, mas não sobre seletividade. Somente a partir das comparações com a origem que podemos estimar a seletividade migratória nesses espaços.

A terceira questão se relaciona aos movimentos pendulares. A intensificação da pendularidade entre os municípios abre oportunidades para a gestão integrada do território, bem como traz maior evidência a alguns problemas como a carência de infraestrutura urbana, o desemprego e a degradação ambiental na região (Cruz \& Terra, 2020). Esses desafios se tornam ainda mais evidentes no leste fluminense, que por um lado é uma região marcada por processos sociais que revelam a integração regional estabelecida pelos municípios, mas, por outro, também é marcada por processos políticos que insistem em fragmentar um espaço demograficamente integrado.

O ponto central que surge a partir dessas questões é que os movimentos populacionais devem ser entendidos como uma parte que pode conectar processos mais amplos, os quais desencadeiam o desenvolvimento das sociedades locais. Essas questões implicam em uma análise dos impactos da mobilidade populacional de forma conjunta, considerando tanto os lugares de origem como os de destino. A partir do entendimento de como esses movimentos modificam as relações existentes entre os territórios, os governos locais podem trabalhar de forma articulada, de modo a trazer benefícios mútuos para as sociedades de origem e de destino. Essas propostas pavimentam o caminho para trabalhos futuros mais consolidados sobre o papel dos movimentos populacionais no processo de crescimento, expansão e integração regional no leste fluminense, assim como podem abrir novas discussões sobre os rumos que a mobilidade espacial da população na região pode seguir no futuro.

\section{Declaração de disponibilidade de dados}

O conjunto de dados que dá suporte aos resultados deste artigo está disponível no SciELO DATA e pode ser acessado em https://doi.org/10.48331/scielodata.CPKXCN

\section{Referências}

Araujo, E. C. de. (2016). Processos Recentes de Urbanização em território fluminense: o fenômeno da dispersão sob a ótica da influência de grandes projetos urbanos. In R. Ojima \& E. Marandola Jr (Eds.), Dispersão Urbana e Mobilidade

Populacional: implicações para o planejamento urbano e regional (1st ed., pp. 91-111). São Paulo: Blücher. 
Arrais, T. A. (2008). A cidade e a região/ a cidade-região: reconhecer processos e construir políticas. Cadernos Metrópole, 20(2), 81-91.

Baeninger, R. (2000). Região, Metrópole e Interior: espaços ganhadores e espaços perdedores nas migrações recentes no Brasil, 1980 - 1996. In R. Baeninger \& D. J. Hogan (Eds.), Redistribuição da População e Meio Ambiente: São Paulo e CentroOeste. Campinas: Textos NEPO no 35.

Baeninger, R. (2010). Crescimento das cidades: metrópole e interior do Brasil. In R. Baeninger (Ed.), População e Cidades: subsídios para o planejamento e para as políticas públicas (1st ed., pp. 209-222). São Paulo: Núcleo de Estudos de População (NEPO) - Unicamp.

Barbieri, A. F. (2015). Reflexões sobre o papel da mobilidade populacional no planejamento para a ocupação da Amazônia. Revista Territórios e Fronteiras, 8(2), 32-44. https://doi.org/10.22228/rt-f.v8i2.458

Carvalho, J. A. M. Campos, J., Pinho, B. A. T. D. de, \& Rigotti, J. I. R. (2016). Efeitos diretos e indiretos das migrações internacionais no Brasil: uma análise a partir do Censo Demográfico 2010. Anais da Associação Brasileira de Estudos Populacionais, 1, 1-21.

Carvalho, J. A. M., \& Rigotti, J. I. R. (1998). Os dados censitários brasileiros sobre migrações internas: algumas sugestões de análise. Revista Brasileira de Estudos da População, 15, 7-17.

Colla, C., Barbieri, A. F., \& Amaral, P. V. (2020). O papel do mercado de trabalho na complementaridade entre a migração e a pendularidade na região metropolitana de Curitiba entre 2000 a 2010. IGpec, 24(2), 97-116.

Cruz, J. L., \& Terra, D. C. T. (2020). Petróleo e porto no norte do estado do Rio de Janeiro, Brasil. Eure, 46(139), $189-208$.

Cunha, J. M. P. da, Farias, L. A. C. de, \& Jakob, A. A. E. (2020). Uma periferia, dois centros: o município de Praia Grande no contexto da formação da macrometrópole paulista no começo do século XXI. Revista Brasileira de Estudos de População, 37, $1-28$.

Federal Register (2000). Federal Register vol 65, $n^{\circ} 249$. Washington, DC.

Galvão, M. V., \& Faissal, S. (1969). Áreas de Pesquisa para Determinação de Áreas Metropolitanas. Revista Geográfica, (70), 57-89. Recuperado em 08 de setembro de 2020 de http://www.jstor.org/stable/40992990

Instituto Brasileiro de Geografia e Estatística - IBGE (2015). Arranjos Populacionais e Concentrações Urbanas no Brasil (2nd ed.; IBGE, ed.). Rio de Janeiro: Instituto Brasileiro de Geografia e Estatística - IBGE.

Instituto Brasileiro de Geografia e Estatística - IBGE (2000). Censo Demográfico, 2000. Recuperado em 08 de setembro de 2019 de http://www.ibge.gov.br

Instituto Brasileiro de Geografia e Estatística - IBGE (2010). Censo Demográfico, 2010. Recuperado em 02 de abril de 2020 de http://www.ibge.gov.br

Instituto Brasileiro de Geografia e Estatística - IBGE (2020). Diretoria de Pesquisas, Coordenação de População e Indicadores Sociais, Estimativas da população residente com data de referência $1^{\circ}$ de julho de 2020.

Instituto Brasileiro de Geografia e Estatística - IBGE (2021). Regiões de Influência das Cidades 2018. Recuperado em 04 de julho de 2021 de http://www.ibge.gov.br

Julien, M. P. (2000). Mesurer un univers urbain en expansion. Economie et Statistique, 336(1), 3-33.

https://doi.org/10.3406/estat.2000.7508

Lee, E. S. (1966). A Theory of Migration. Demography, 3(1), 47-57. https://doi.org/Book Review

Lobo, C., Cardoso, L., \& Almeida, I. L. de. (2018). Mobilidade pendular e integração regional: uma metodologia de análise para as regiões metropolitanas de Belo Horizonte, Rio de Janeiro e São Paulo. Cadernos Metrópole, 20(41), 171-189. https://doi.org/10.1590/2236-9996.2018-4108

Moura, R., Castello Branco, M. L. G., \& Firkowski, O. L. C. de F. (2005). Movimento pendular e perspectivas de pesquisas em aglomerados urbanos. São Paulo Em Perspectiva, 19(4), 121-133. https://doi.org/10.1590/s0102-88392005000400008

Moura, R., Delgado, P., \& Costa, M. A. (2013). Movimento Pendular e Políticas Públicas: algumas possibilidades inspiradas numa tipologia dos municípios brasileiros. In R. Boueri \& M. A. Costa (Eds.), Brasil em Desenvolvimento 2013: Estado, Planejamento e Políticas Públicas (pp. 665-688). Brasília: Instituto de Pesquisa Econômica Aplicada. 


\section{Migrações internas e mobilidade pendular}

Ojima, R., \& Marandola Jr., E. (2012). Mobilidade populacional e um novo significado para as cidades: dispersão urbana e reflexiva na dinâmica regional não metropolitana. Revista Brasileira de Estudos Urbanos e Regionais, 14(2), $103-116$. https://doi.org/10.22296/2317-1529.2012v14n2p103

Ojima, R., Mandarola Jr., E., Pereira, R. H. M., \& Silva, R. B. da. (2010). 0 estigma de morar longe da cidade: repensando o consenso sobre as "cidades-dormitório" no Brasil. Cadernos Metrópole, 12(24), 395-415. https://doi.org/10.1590/5896

Paganoto, F. (2012). Novos contextos, novos padrões: o mercado imobiliário e os rearranjos na mobilidade espacial da população na Região Metropolitana do Rio de Janeiro. Revista Tamoios, 8(1), 42-48.

Passarelli-Araujo, H., \& Souza, J. de. (2020). Movimentos pendulares e integração regional no leste fluminense. Revista Brasileira de Estudos de População, 37, 1-23. https://doi.org/10.20947/s0102-3098a0126

Pereira, R. H. M., \& Herrero, V. (2009). Mobilidade pendular: uma proposta teórico-metodológica. In Texto para discussão $n^{o}$ 1395 (1st ed.). Brasília: Instituto de Pesquisa Econômica Aplicada.

Piquet, R., Givisiez, G. H. N., \& Oliveira, E. L. de. (2008). A nova centralidade de Campos dos Goytacazes: o velho e o novo contexto regional. RDE - Revista de Desenvolvimento Econômico, 9(16), 39-58.

Rodríguez-Vignoli, J., \& Rowe, F. (2018). How is internal migration reshaping metropolitan populations in Latin America? A new method and new evidence. Population Studies, 72(2), 253-273. https://doi.org/10.1080/00324728.2017.1416155

Scott, A., Agnew, J., Soja, E. W., \& Storper, M (2001). Cidades-regiões globais. Espaço \& Debates, 41(1), 11-25.

Siegel, J. S., \& Swanson, D. A. (2004). The Methods and Materials of Demography. In D. A. Swanson \& J. S. Siegel (Eds.), The Methods and Materials of Demography (2nd ed.). California: Elsevier Academic Press.

Silva, K. A. A. Alonso, R. M. de, Chaves, L. F., \& Cunha, J. M. P. da. (2016). Crescimento das cidades médias e interiorização da migração: realidade ou mito? Geografias, 93-114. https://doi.org/10.5151/socsci-ix-enm-st2-4

Silva, S. C. da. (2015). Globalização e o Circuito Espacial de Produção Petrolífero: As Cidades da Informação e as Cidades da Extração. XI Encontro Nacional da Anpege, 4774-4785.

Souza, J. de, \& Frutuozo, J. V. de P. (2018). Rio de Janeiro: considerações sobre os processos de expansão urbana e interiorização do crescimento (1980-2010). Urbe. Revista Brasileira de Gestão Urbana, 10(1), 124-139.

https://doi.org/10.1590/2175-3369.010.001.ao12

Souza, J. de, Terra, D. C.T., \& Campos, M. M. (2015). Mobilidade populacional e as novas espacialidades urbanas: municípios da Ompetro, Rio de Janeiro (2000-2010). EURE (Santiago), 41(123), 53-80. https://doi.org/10.4067/S0250-

71612015000300003

Souza, J. de, \& Terra, D. C. T. (2015). Indústria petrolífera, mercado de trabalho e nível de dependência da mão de obra exógena nos municípios produtores de petróleo da Bacia de Campos, RJ. Revista Brasileira de Estudos Urbanos e Regionais, 17(1), 123. https://doi.org/10.22296/2317-1529.2015v17n1p123

Souza, J. de, \& Terra, D. C. T. (2017). Rio de Janeiro: rumo a uma nova região metropolitana? Cadernos Metrópole, 19(40), 817-840. https://doi.org/10.1590/2236-9996.2017-4006

Souza, J. de, Passarelli-Araujo, H., \& Vasconcelos Júnior, A. F. da S. (2019). Macaé: uma cidade em movimento. In S. R. de A. e Silva \& M. R. de Carvalho (Eds.), Macaé, do caos ao conhecimento: olhares acadêmicos sobre o cenário de crise econômica (1st ed., pp. 64-80). Macaé-RJ: Observatório da cidade de Macaé.

Souza, J., \& Terra, D. C. T. (2020). Migrações, pendularidades e mercado de trabalho no segmento upstream da indústria do petróleo na bacia de campos. Eure, 46(137), 157-180. https://doi.org/10.4067/S0250-71612020000100157

Terra, D. C. T., \& Azevedo, N. L. de. (2019). Limites e Possibilidades da construção de Arranjos político-institucionais de cooperação intermunicipal na Bacia de Campos. In S. R. de A. e Silva \& M. R. de Carvalho (Eds.), Macaé, do caos ao conhecimento: olhares acadêmicos sobre o cenário de crise econômica (1st ed., pp. 459-502). Macaé: Prefeitura Municipal de Macaé.

\section{Editor responsável: Rodrigo Firmino}

Recebido: 13 abr. 2021

Aprovado: 30 ago. 2021 